\title{
Treating Depression and Compensatory Narcissistic Personality Style in a Man With Chronic Lyme Disease
}

\author{
Melissa J. Leedy \\ Melissa Jackson \\ Oklahoma State University, Stillwater \\ Jennifer L. Callahan \\ University of North Texas, Denton
}

\begin{abstract}
The following case study illustrates a client-centered, cognitive-behavioral approach to the psychological treatment of Mr. M, a 41-year-old male diagnosed with chronic Lyme disease, a mood disorder from Lyme disease, and narcissistic personality disorder. Mr. M's personality difficulties are conceptualized as representing compensatory narcissism, a strategic way of coping with feelings of insecurity. The goals of treatment included positively integrating Mr. M's chronic illness into his identity, decreasing depressive symptoms, and improving his interpersonal skills. Treatment was successful in decreasing both Mr. M's depressive symptoms and his narcissistic orientation to thinking and interacting with others.
\end{abstract}

Keywords: compensatory narcissism; narcissistic personality disorder; idiographic assessment; Lyme disease

\section{Theoretical and Research Basis}

The following case study illustrates an approach to treating depression and compensatory narcissistic personality style in a man with a chronic medical illness, Lyme disease (LD). LD is a tick-borne, multisystemic illness that can result in a host of deficits, including neurological, arthritic, dermatological, ophthalmological, cardiac, and psychiatric distress (Westervelt \& McCaffrey, 2002), though symptom presentation in each domain differs according to stage of illness. For the purposes of this article, a review of symptoms will be limited to those typically occurring in the late/chronic stage, as those are the most relevant for the following case presentation.

The label late/chronic LD is given to patients whose medical symptoms persist despite undergoing a standard course of antibiotic treatment (Fallon, Kochevar, \& Nields, 1998). Common, but not universal, symptoms during this stage often include arthritis, encephalitis, polyneuropathy, extreme fatigue, sensory loss, word-finding difficulties, sleep disturbances, sensitivity to light and sound, spatial disorientation, irritability (Westervelt \& McCaffrey, 2002), memory and attention disturbances (Tager \& Fallon, 2001), and a plethora of psychiatric 
symptoms that span most Axis I and Axis II categories (Fallon \& Nields, 1994). To address the full scope of symptoms, treatment recommendations for patients with chronic LD typically include medication management (Wormser et al., 2000), cognitive rehabilitation, and psychological care (Tager \& Fallon, 2001).

Depression has been noted to be a particularly common psychiatric disturbance in patients with LD (Fallon \& Nields, 1994; Kaplan et al., 1999; Krupp et al., 1991); in fact, this is the primary reason that the individual in this case study sought treatment. Yet researchers are unclear if depressive symptoms are caused by the disease itself or emerge in reaction to the experience of living with a chronic illness (Elkins, Pollina, Scheffer, \& Krupp, 1999). Confusion on the etiology of depression in LD primarily stems from research indicating that scores on depression measures do not significantly correlate with other indicators of disease severity (Elkins et al., 1999; Keilp, Corbera, \& Slavov, 2006). Regardless, a review of controlled and case studies suggests that patients with LD are more likely to experience depressive symptoms compared with control groups or other medically ill patients (Fallon \& Nields, 1994). Unfortunately, the literature does not provide any guidelines for what type of psychological treatment is effective with individuals suffering from LD.

Aside from depressive symptoms, Mr. M presented with a distinctly narcissistic orientation and exhibited 6 of 9 criteria for narcissistic personality disorder (NPD; American Psychiatric Association, 2000), including (a) preoccupation with fantasies of grandiosity, (b) a belief that he was unique and could only be understood by a select number of people, (c) a sense of entitlement that leads to unreasonable expectations of others, (d) an interpersonally exploitative nature, (e) a lack of empathy toward others, and (f) an arrogant, even haughty, attitude.

According to a prominent personality disorder theorist, Theodore Millon (1996), individuals with NPD tend to live in a fantasy-like world, which may be the result of having learned that they must rely on themselves to feel safe and to develop a high self-esteem. He more specifically conceptualizes NPD as having several different subtypes, one of which is the compensatory narcissist. According to Millon, individuals displaying compensatory narcissism fundamentally differ from the other subtypes in that the origins of their narcissistic behaviors and thinking do not stem from genuine feelings of grandiosity. Instead, their feelings of grandiose self-worth are a strategic maneuver to compensate for deprivations experienced earlier in life that resulted in a deep sense of insecurity and weakness. Supporting this theory, research indicates that such comparisons result in positive affect and may serve as an effective strategy to bolster self-esteem (Bogart, Benotsch, \& Pavlovic, 2004). Millon points out that, in essence, adopting a narcissistic attitude is a way to protect the self from feeling defective and from being the potential target of critical judgments from others. Furthermore, Millon asserts that people with compensatory narcissism are highly anxious and sensitive to the possibility of negative judgments. They are likely to feel shame and humiliation because they "know they are frauds at some level" (p. 412).

\section{Case Presentation}

This case illustrates Mr. M, a 41-year-old, never-married, heterosexual, White male. He began exhibiting symptoms of LD at age 16 and consistently sought medical attention 
over many years for these symptoms. He received several medical and psychiatric diagnoses that were ultimately incorrect, including delusional disorder, schizophrenia, and temporal lobe epilepsy. Finally, Mr. M. was diagnosed with LD in his mid-30s and immediately began the recommended medical treatment. Although compliant with all treatment recommendations, his symptoms only partially resolved.

\section{Presenting Complaints}

Mr. M presented with moderate to severe symptoms of depression, as measured by the Beck Depression Inventory-II (BDI-II; Beck, Steer, \& Brown, 1996).

He specifically reported feeling adrift and uncertain about how to build his life while having a chronic illness and acknowledged fear that others would be unable to appreciate his capabilities and be distracted by his medical condition. He indicated moderate suicidal ideation at intake and in subsequent therapy sessions, although he denied having a specific plan of action and had no history of attempted suicide.

\section{History}

Mr. $\mathrm{M}$ is the youngest of five siblings and was raised with his family of origin in an urban setting. His childhood experiences were unremarkable, and he reported having a typical, happy childhood. He described his parents as conservative and considered his father to be "cold and distant," but he was close with his mother, whom he described as "prim and proper." At the time of treatment, he maintained a close relationship with his mother and siblings but rarely spoke with his father.

Socially, Mr. M reported having few friends, noting that many of his friendships dissipated after becoming symptomatic with LD. Although he had several long-term, intimate relationships with female partners in early adulthood, he described these women as being "emotionally dependent" on him and ultimately having a negative impact on his self-perception.

Aside from LD, Mr. M's medical history was essentially unremarkable. He first began experiencing neurological and psychological symptoms of LD at age 16, which included feelings of extreme depersonalization, anxiety, headaches, concentration difficulties, fatigue, circadian sleep disturbance, and depression. In addition, he reported that his symptoms fluctuated along a continuum over time, from extremely severe (e.g., paranoid delusions) to asymptomatic. The fluctuating course and unpredictable symptom severity significantly interfered with both his academic pursuits and his interpersonal relationships, leading him to discontinue his education and increasing social isolation. The fluctuating nature of his illness also prevented him from maintaining steady employment, with only brief periods of employment.

\section{Assessment}

At intake, Mr. M completed a semistructured interview, the BDI-II, the Beck Anxiety Inventory (Beck, Epstein, Brown, \& Steer, 1988), and the Symptom Checklist-90-Revised 
(Derogatis, 1994). Results indicated that Mr. M was experiencing moderate to severe depression and moderate anxiety. His subjective endorsement of symptoms on the semistructured interview provided support for a diagnosis of mood disorder because of chronic LD with depressive features.

For purposes of examiner training, Mr. M agreed to participate in personality assessment, conducted by a second student clinician, in which he completed the Minnesota Multiphasic Personality Inventory-2 (MMPI-2; Hathaway \& McKinley, 1989), the Rotter Incomplete Sentences Test Blank (RISB; Rotter \& Rafferty, 1950), and the Rorschach Inkblot Test (Exner, 1993; Rorschach, 1921/1942). On the MMPI-2, clinical elevations were observed on Scales 1, 2, 4, 6, 7, and 8, with the content and supplementary scales further indicating health concerns, anxiety, and overall social maladjustment. Overall, the MMPI-2 results suggested that Mr. M. was considerably distressed, with low morale, low self-esteem, and hopelessness. Although Mr. M described himself as simply socially introverted, his MMPI-2 responses suggested feelings of being misunderstood by others, resulting in loneliness, emptiness, and suspiciousness of others.

Results also suggested preoccupation with physical functioning and frequent worry about health-related issues, as might be expected in an individual with a history of unsatisfactory medical attention and a chronic illness. Response patterns also demonstrated abnormal thought patterns and beliefs, feelings of unreality, and unusual perceptual or sensory experiences (e.g., feelings of burning, numbness, and crawling sensations on his body). Again, such symptoms are known to be characteristic of chronic LD.

Responses on the RISB also indicated acute emotional distress, with the most prominent themes centering on feelings of inadequacy and low self-esteem. Less prominent, but still notable, were responses acknowledging feelings of depersonalization and potentially suggestive of delusional thought patterns.

Mr. M's Rorschach was scored and interpreted using the Exner system. Results were congruent with the MMPI-2 and the RISB and indicated the potential of thought disturbance and frequent and intense depressive episodes and health preoccupations. With respect to selfperception, the pattern of Rorschach responses indicated a pervasive pessimistic egocentrism. In addition, responses indicated that Mr. M's self-image was largely based on fantasized conceptualizations of self rather than founded in actual feedback from others. This, coupled with problems related to accurately drawing meaning from information, appear to have led to distorted self-views and a heightened level of awareness regarding perceived flaws.

Within the interpersonal domain, Mr. M.'s responses on the Rorschach suggested that he regards his environment with a sense of mistrust and suspicion. Overall, Rorschach responses suggested that Mr. M. had a negativistic or oppositional attitude toward the environment, likely impeding the formation of healthy relationships with others. Similar to response patterns on the MMPI-2 and RISB, his responses suggested excessive concern with issues of personal space and, perhaps, a lack of interest in interacting with others. Unfortunately, his ideational style suggested relative inflexibility. Coupled with his vulnerability toward being perceptually inaccurate, this could result in Mr. M being inaccurate, yet also unyielding, in understanding the perspectives of others. As a result, others may get the impression that Mr. M has little concern regarding their opinions or values.

Mr. M was aware that a clinician he worked with several years previously had diagnosed him with NPD, and this was a sensitive topic for him. Mr. M's fear of being "labeled" NPD 
was so prominent that he chose not to receive feedback from the personality assessment. Given Millon's (1996) conceptualization that hypersensitivity can be expected in those exhibiting compensatory narcissism, it was decided that specific assessment exploring the hypothesis of a compensatory narcissism would be held off until later in treatment (i.e., Session 28).

As treatment progressed, Mr. M became more aware of his narcissistic behaviors or comments and invited the student clinician to provide him with feedback on such occasions. For example, when discussing his thoughts about himself in relation to others, he began to make statements such as, "That sounds narcissistic, doesn't it?" This progression seemed to be the result of empathy and a nonjudgmental stance on behalf of the clinician. After several such exchanges over successive sessions, he was administered an assessment to test the specific hypothesis that his narcissism was compensatory in nature. Specifically, the therapist administered the Hypersensitive Narcissism Scale (HNS; Hendin \& Cheek, 1997) using Idiogrid software (Grice, 2002), which is based on the repertory grid approach. First introduced by Kelly as a part of personal construct theory, repertory grids continue to be useful in understanding how individuals view the relationship between themselves and important elements in their lives (Mason, 2003).

Using Idiogrid, Mr. M responded to each item of the HNS multiple times so that his perceptions of self and others could be plotted and compared. He was asked to respond to each question from the following perspectives: his self at the start of therapy, his current self, his ideal self, his self when chronically ill, someone he admires, someone he dislikes, and his therapist. The resulting self-identity grid (see Figure 1) indicates that Mr. M viewed his self at start of therapy and his self when chronically ill as similar. Unfortunately, though not surprisingly, these were similar to how he rated someone he dislikes. As expected, his view of his ideal self was similar to someone he admired. If Mr. M's current self had been located closely to his ideal self, the conceptualization that his narcissism was compensatory in nature would not have been supported and may have suggested a more typical presentation of narcissism. However, results of the HNS Idiogrid assessment supported the hypotheses that Mr. M's narcissism was not based on a genuine sense of grandiosity and that his illness likely contributed to his need to use a maladaptive strategy to increase his self-esteem.

\section{Case Conceptualization}

Mr. M presented for therapy with chronic LD, symptoms of depression, poor interpersonal skills, feelings of social isolation, low self-esteem, hypersensitivity to others' reactions toward him, and a narcissistic personality style. Using a cognitive-behavioral conceptualization, it was apparent that one of Mr. M's core beliefs was that he was defective because of his diagnosis of LD. This belief subsequently led to a belief that others did not like him and could not relate to him. He felt utterly alone and misunderstood.

It is noteworthy that Mr. M became ill in adolescence, a developmental period marked by a focus on achieving a sense of personal identity and interpersonal skills (Erikson, 1968). Perhaps as a result of Mr. M being necessarily preoccupied with his medical symptoms, his self-described identity was presented to the therapist more as a collection of symptoms. Furthermore, illness precluded Mr. M from taking advantage of many typical 


\section{Figure 1}

Self-Identify Grid Generated by Mr. M

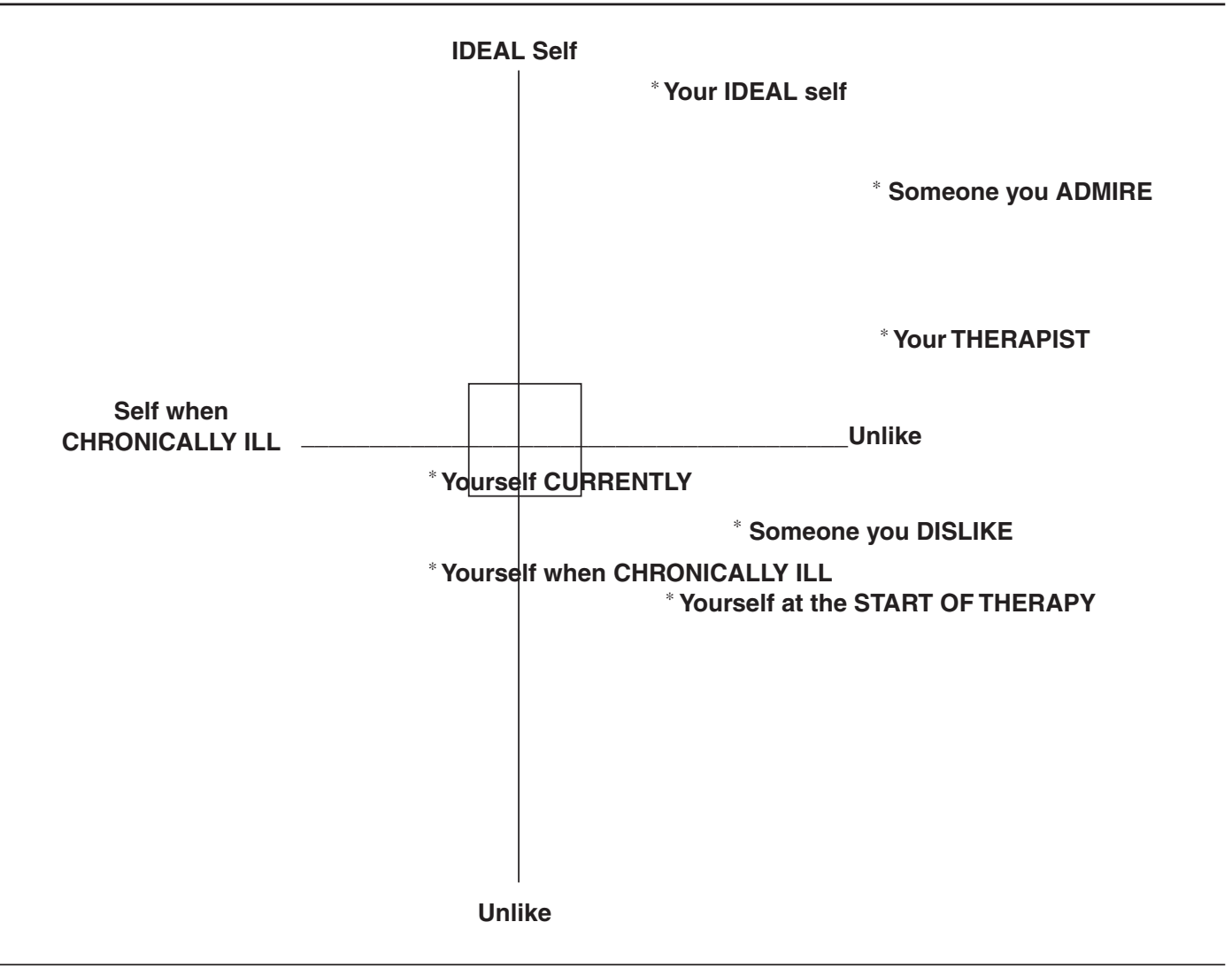

adolescent activities for developing and practicing emerging interpersonal skills. At the start of therapy, Mr. M's compromised sense of self and poorly developed social skills appeared to have resulted in long-standing feelings of social inadequacy and a general sense of defectiveness.

After getting to know Mr. M, it became clear that his belief that he was "defective" resulted in low self-esteem and extreme hypersensitivity to others' reactions toward him. This resulted in limited social engagement, as social situations were anxiety provoking and typically not reinforcing for him. Unfortunately, his belief exacerbated his experience of depression by limiting social support and reinforcing his belief that he was so defective no one could like or relate to him.

Mr. M's hypersensitivity also resulted in him interpreting others' responses as critical and rejecting. Indeed, over time Mr. M actually began to elicit such responses from others (e.g., by injecting intravenous medication into his chest while in public places, when privacy was otherwise available). In the face of the predictable response of disapproval, Mr. $\mathrm{M}$ described responding in a superior and dismissive manner, later citing such exchanges as reasons to further limit interpersonal contact. Observing (i.e., within the clinic waiting 
room) and learning of such exchanges was one of the first clues that led to focusing on Millon's (1996) view of compensatory narcissism.

Aside from a disingenuous façade of superiority, Millon (1996) states that individuals who exhibit a compensatory narcissistic personality style may often become engrossed in an imaginary world that is self-created and may appear delusional. On several occasions, Mr. M spontaneously expressed that he felt that he lived in an imaginary world and was often fearful of sounding "crazy" during sessions, which may have been a reflection of his previous experience with mental health professionals who did, in fact, deem him delusional.

\section{Course of Treatment and Assessment of Progress}

As noted, Mr. M presented for therapy reporting feelings of depression and interpersonal difficulties. He presented with a somewhat blunted yet pleasant affect. His expressed thoughts were devoid of bizarre content, although a prominent self-orientation was apparent. Mr. M evidenced notable difficulty in articulating his thoughts. Most commonly, this was the result of very tangential speech, with Mr. M ultimately forgetting the topic or question at hand. Finally, he often appeared agitated and restless during the initial period of treatment. During the course of treatment, Mr. M maintained consistent motivation to engage in psychotherapy.

Mr. M was seen weekly for 37 sessions. He consistently arrived on time for his appointments and only occasionally cancelled. At the beginning of treatment, Mr. M was weary of seeking psychological services because of past, reportedly negative, treatment encounters. Initially, Mr. M and the student clinician discussed his experience of LD and detailed his medical and psychiatric history. Although his presentation was typically pleasant, at times the student clinician felt that Mr. M was questioning, or even degrading, her intellectual abilities.

A fundamental goal throughout treatment was to establish and maintain a strong therapeutic alliance. Millon (1996) argues that a strong alliance is necessary to provide feedback about NPD, as "the best therapeutic outcomes may come from honest interpretations presented in a tone of approval and acceptance" (p. 424). Millon's advice is supported by research that indicates that narcissistic individuals may have a hostile reaction in response to receiving negative feedback (Bushman \& Baumeister, 1998; Morf \& Rhodewalt, 1993; Rhodewalt \& Morf, 1998). Thus, the therapist had to consider the quality of the therapeutic relationship before openly assessing and discussing Mr. M's narcissism. It appeared that spending time developing a strong, genuine therapeutic alliance was beneficial, as during the course of treatment, Mr. M described a deep sense of trust in the student therapist.

The goals of the initial treatment plan included (a) positively integrating Mr. M's chronic illness into his identity, (b) decreasing depressive symptoms, and (c) improving interpersonal skills, including decreasing narcissistic symptoms. The short-term objectives and therapeutic interventions identified are provided in Table 1.

Although a cognitive-behavioral framework was used to conceptualize the case and determine specific interventions, the student clinician typically used a client-centered model of treatment during therapy sessions while integrating cognitive-behavioral therapy techniques. This approach was used to complement Mr. M's overt desire for a supportive psychotherapy approach while recognizing and treating his tendency to entertain maladaptive 


\section{Table 1}

Treatment Plan for Mr. M

Short-Term Objectives

1. Describe emotional impact of, and general meaning of, chronic illness and how illness affects life goals, thoughts, and feelings.

2a. Identify sources of depressed mood.

2b. Engage in recreational activities.

2c. Increase social contact.

$2 \mathrm{~d}$. Identify/challenge negative and dysfunctional thoughts.

3. Increase adaptive interpersonal skills and decrease narcissism.
Therapeutic Interventions

Read, complete activities, and discuss relevant sections in The Chronic Illness Workbook by Patricia Fennell (2001).

Process feelings of grief and loss associated with chronic health condition.

Explore the emotional impact of life changes associated with medical condition.

Keep journal of daily symptoms and associated life changes.

Explore ways in which the medical community impacts the self. Identify alternative explanations for systemic weaknesses. Identify positive aspects of system.

Monitor symptoms of depression and onset of more intense symptoms; differentiate between mood and illness.

Develop and implement pleasant activities list.

Develop plan to join activity group or support group.

Record daily activities and associated thoughts. Challenge dysfunctional thoughts and identify alternative interpretations.

Develop and maintain a strong therapeutic alliance.

Maintain a genuine and empathetic therapeutic attitude.

Use role plays or in vivo exposure techniques to: (a) teach basic communication skills, (b) develop empathy skills by using role-reversal techniques and exploring consequences of behavior/communication on others, (c) ask questions to understand others' points of view, and (d) practice developing trust by sharing small pieces of personal information with others and observe outcome.

thoughts that maintained many of his symptoms. Using a client-centered approach also seemed to enhance the therapeutic alliance and Mr. M's respect for the therapist, as his narcissism was unconditionally accepted with the corresponding effect of Mr. M becoming less focused on disputing the therapist's qualifications or feedback.

\section{Positively Integrate Chronic Illness Into Self-Identity}

When Mr. M first began treatment, it was evident that his sense of self was highly dependent on his illness. For example, he was unable to identify positive or negative attributes about himself, state goals, or even recall much of his personal history without repetitive references to his illness. Thus, much of the early work in therapy focused on creating a more positive self-identity that would take into account his illness but would not entirely define his identity. The Chronic Illness Workbook (Fennell, 2001) proved to be a resourceful text for this goal. In this phase of therapy, the therapist used a client-centered approach that allowed Mr. $M$ to determine the agenda of therapy, including the sections of the text that were important for him to discuss. Mr. M expressed that reading and discussing the text helped 
Figure 2

Mr. M's Scores on the Beck Depression Inventory-II (BDI-II) During Treatment and at 2-Month Posttreatment Follow-Up

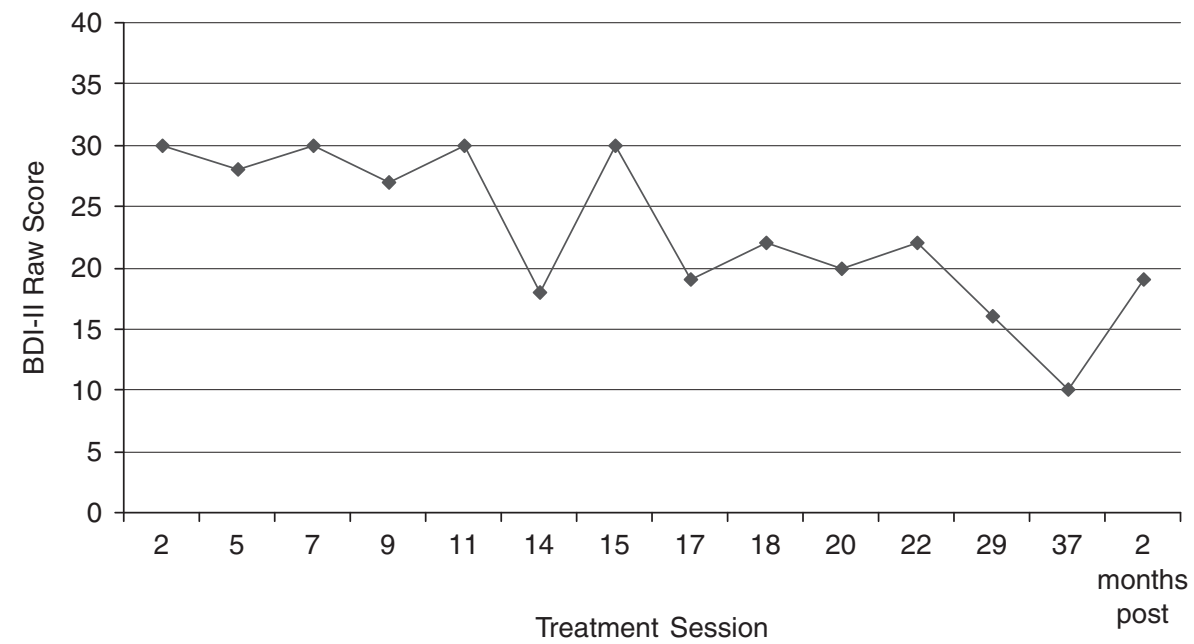

Note: Qualitative meanings conventionally associated with BDI-II scores: 63 to $30=$ extremely severe, 29 to 19 $=$ moderate-severe, 18 to $10=$ mild-moderate, 9 to $0=$ normal.

him feel less isolated in his experience of LD and helped him gain insight into his thoughts, feelings, and behaviors during both symptomatic and asymptomatic phases.

\section{Decrease Depression}

The student clinician helped Mr. M identify and challenge cognitive distortions, which were largely characterized by dichotomous thinking and mind-reading errors. He enthusiastically responded to the intellectual challenge posed by identifying and countering these distortions. In addition, Mr. M was encouraged to incorporate some pleasant events, including social contacts, into his week, which he did periodically.

In the interest of monitoring his depressive symptoms, Mr. M completed the BDI-II biweekly in the first half of treatment and then approximately once each month thereafter. Figure 2 illustrates his BDI-II scores during the course of treatment. As indicated, Mr. M's depression scores decreased from extreme-severe to mild-moderate. At the end of treatment, Mr. M subjectively reported that he did not feel depressed and that the few symptoms he continued to endorse on the BDI-II were vegetative symptoms that he felt reflected symptoms of his LD rather than depression as he experienced it at intake.

\section{Improve Interpersonal Skills and Decrease Narcissism}

Mr. M also presented with a number of interpersonal skill deficits. Most problematic among these were (a) failure to make appropriate eye contact, (b) a rigid, demanding manner of asking questions, and (c) domination of conversations. After identifying and discussing these 
deficits, including discussion of contrasting appropriate behaviors, an in vivo interpersonal exchange was implemented. The primary student clinician instructed another student clinician ("Gina"), unfamiliar to Mr. M, to have a "typical" conversation. Mr. M was simply instructed to initiate and maintain a conversation with Gina for approximately 30 minutes. With Mr. M's and Gina's consent, the conversation was recorded. Mr. M and the student clinician then reviewed the videotape during the course of two subsequent sessions.

While reviewing the recording, the student clinician and Mr. M focused on several areas: identifying how his self-defeating thoughts and worry affected his interpersonal behavior, providing feedback on the accuracy of his thoughts compared to Gina's responses and body language, providing a view of how others may perceive his behavior as intimidating and narcissistic, teaching him how to reframe closed-ended questions as open ended, learning how to express empathy, and identifying his interpersonal strengths. Mr. M noted that he learned a great deal from combining his self-evaluation with the clinician's feedback. In subsequent sessions, as he described social interactions, he increasingly demonstrated use of these strategies.

\section{Complicating Factors}

It is unclear if, and what percentage of, Mr. M's depressive symptoms were a function of his medical illness or if they were independent psychological problems. As previously noted, depression is a frequent comorbid disorder of LD, but it is not known if depression is a manifestation of the disease or the result of living with a chronic illness. Furthermore, Mr. M's disease management required a host of medications, which also may have contributed to his depression. In any event, cognitive therapy and behavioral activation were effective at reducing and maintaining the reduction in depressive symptoms.

An additional complicating factor involved discussing Mr. M's narcissism in a way that did not exacerbate his depression. As previously noted, specific discussions of his narcissism did not take place until the therapist felt that the therapeutic alliance was sufficiently strong to support challenges to this particular aspect of his functioning and his depressive symptoms had diminished substantially. Aside from attending to the timing of interventions, two techniques seemed to be particularly beneficial: (a) maintaining a genuine, nonjudgmental attitude and (b) sharing the conceptualization that Mr. M's narcissism was compensatory. Mr. M demonstrated openness to the suggestion that such an orientation may have been functional earlier in his life, when he was struggling to find any symptomatic relief from LD. In this way, the therapist was able to reframe Mr. M's narcissism as a long-standing coping mechanism that was no longer adaptive, rather than as a stable aspect of his personality that could not be modified. This reframe appeared to allow Mr. M to incorporate this feedback in a nondefensive manner that did not negatively affect his sense of general well-being.

\section{Managed Care Considerations}

Treatment occurred in a training clinic that used a sliding scale to determine session fees and did not accept insurance. Thus, Mr. M paid for his sessions out of pocket. This did not appear to be a limiting factor to his treatment. 


\section{Follow-Up}

After successfully meeting his therapeutic goals, Mr. M and the student clinician agreed to discontinue treatment. Mr. M made substantial improvements that included a more balanced integration of his illness into his self-identity, decreases in depressive symptoms, improved interpersonal skills, recognition of his narcissistic thoughts, and decreases in his narcissistic manner of responding to and interacting with others. Shortly after terminating treatment, the student clinician left her position in the clinic because of changing practicum sites. Mr. M was kind enough to return and complete the BDI-II approximately 2 months posttreatment for follow-up purposes, but no other follow-up information is available.

\section{Treatment Implications of the Case}

The therapist's attitude was an important, though nonspecific, intervention. Although not the first theorist to emphasize the importance of the therapeutic relationship (e.g., Rogers, 1952), Millon (1996) states that "good therapeutic gains will result when the patient internalizes the therapist's empathetic acceptance of the patient's faults and deficits" (p. 424). More specifically, research indicates that such an attitude may be necessary to help individuals with NPD accept negative feedback (Bushman \& Baumeister, 1998; Morf \& Rhodewalt, 1993; Rhodewalt \& Morf, 1998).

When Mr. M presented for treatment, he was experiencing a range of difficulties, many of which seemed related to LD. However, the literature on treating psychiatric difficulties in patients with LD is slim and provided little guidance. Issues of self-identity were a major problem for Mr. M, and he responded well to using a workbook that focused on the difficulties that individuals with chronic illness experience. Based on Mr. M's subjective report, he began to feel less isolated and realized that others might be sensitive to his experiences.

In regard to his depressive symptoms, Mr. M responded well to cognitive therapy, which has been shown to be one effective strategy for treating depression (Young, Weinberger, \& Beck, 2001). The in vivo exposure intervention seemed very effective in improving some of Mr. M's interpersonal skill deficits. This intervention also presented an opportunity to continue challenging his dysfunctional thoughts and help him create a more realistic view of himself. In addition, while reviewing the exposure video, Mr. M displayed increasing spontaneous recognition of his narcissism and was receptive to feedback about how he could be more empathetic and others oriented. Based on his report, he was successful at incorporating this feedback into his interactions with others, and such interactions substantially increased after the implementation of this intervention.

\section{Recommendations to Clinicians and Students}

It is understandable that the stress of living with a chronic illness may produce a host of psychological maladjustments. It is important for clinicians to determine if a physical illness accounts for psychological symptoms or if a client's presentation is truly the result of a psychological syndrome (Morrison, 1997) when considering a case formulation. Similarly, if a client presents with medical and psychiatric symptoms, it is important for 
clinicians to recognize the influence of medical illness on psychological functioning, and vice versa, in developing an appropriate treatment plan.

In addition, clinicians treating clients with a medical illness should monitor the presentation of both psychological and medical symptoms so that the treatment plan can be modified as needed and/or appropriate referrals can be made. Finally, clinicians should be aware of the clients' preferred strategies for coping with their medical illness, especially those that are maladaptive. Mental health providers can provide a unique service to clients by helping them develop more adaptive coping strategies that may enhance their quality of life.

An additional recommendation, perhaps especially salient for student therapists, is to be aware of and manage countertransference issues. As noted, early in treatment the student therapist felt that Mr. M was challenging her competency. Such a challenge is likely to reinforce the so-called imposter phenomenon that beginning therapists may experience. The imposter phenomenon describes one's belief that (a) others' perceptions of a person are more favorable than what is actually warranted, (b) others will learn that the person is a fraud, and (c) success is not the result of personal abilities (Leary, Patton, Orlando, \& Funk, 2000). The therapist must have an in-depth understanding of narcissism to recognize that an attack on his or her competency may simply be a reflection of the narcissistic orientation with little bearing on the therapist's actual abilities. Supervisors should be mindful and sensitive to these issues and encourage student therapists to process thoughts and feelings that arise from such challenges to avoid possible problems in developing the therapeutic alliance with such clients.

Finally, when developing a treatment plan, therapists should first consult the literature. Suggestions on how to treat unique clients and problems may not be illustrated in the literature, but therapists may be able to identify similarities between their client and presenting problem and those noted in the literature that provide a useful starting point. In addition, therapists should seek consultation from colleagues and continually check in with their clients to monitor their subjective sense of treatment progress.

\section{References}

American Psychiatric Association. (2000). Diagnostic and statistical manual of mental disorders (4th ed., text revision). Washington, DC: Author.

Beck, A. T., Epstein, N., Brown, G., \& Steer, R. A. (1988). An inventory for measuring clinical anxiety: Psychometric properties. Journal of Consulting and Clinical Psychology, 56, 893-897.

Beck, A. T., Steer, R. A., \& Brown, G. K. (1996). Beck depression inventory (2nd ed.). San Antonio, TX: The Psychological Corporation.

Bogart, L. M., Benotsch, E. G., \& Pavlovic, J. D. (2004). Feeling superior but threatened: The relation of narcissism to social comparison. Basic and Applied Social Psychology, 26, 35-44.

Bushman, B. J., \& Baumeister, R. F. (1998). Threatened egotism, narcissism, self-esteem, and direct and displaced aggression: Does self-love or self-hate lead to violence? Journal of Personality and Social Psychology, 75, 219-229.

Derogatis, L. R. (1994). SCL-90-R Symptom Checklist-90-R. Minneapolis, MN: National Computer System.

Elkins, L. E., Pollina, D. A., Scheffer, S. R., \& Krupp, L. B. (1999). Psychological states and neuropsychological performances in chronic Lyme disease. Applied Neuropsychology, 6, 19-26.

Erikson, E. H. (1968). Identity: Youth and crisis. New York: Norton.

Exner, J. E. (1993). The Rorschach: A comprehensive system (Vol. 1). New York: John Wiley.

Fallon, B. A., Kochevar, J., \& Nields, J. A. (1998). The underdiagnosis of neuropsychiatric Lyme disease in children and adults. Psychiatric Clinics of North America, 21, 693-703. 
Fallon, B. A., \& Nields, J. A. (1994). Lyme disease: A neuropsychiatric illness. American Journal of Psychiatry, $151,1571-1583$.

Fennell, P. A. (2001). The chronic illness workbook. Oakland, CA: New Harbinger.

Grice, J. (2002). Idiogrid: Software for the management and analysis of repertory grids. Behavior Research Methods, Instruments, and Computers, 34, 338-341.

Hathaway, S. R., \& McKinley, J. C. (1989). Minnesota Multiphasic Personality Inventory-2. Minneapolis: University of Minnesota Press.

Hendin, H. M., \& Cheek, J. M. (1997). Assessing hypersensitive narcissism: A re-examination of Murray's Narcissism Scale. Journal of Research in Personality, 31, 588-599.

Kaplan, R. F., Jones-Woodward, L., Workman, K., Steere, A. C., Logigian, E. L., \& Meadows, M. (1999). Neuropsychological deficits in Lyme disease patients with and without evidence of central nervous system pathology. Applied Neuropsychology, 6, 3-11.

Keilp, J. G., Corbera, K., \& Slavov, I. (2006). WAIS-III and WMS-III performance in chronic Lyme disease. Journal of the International Neuropsychological Society, 12, 119-129.

Krupp, L. B., Masur, D., Schwartz, J., Coyle, P. K., Langenbach, L. J., Fernquist, S. K., et al. (1991). Cognitive functioning in late Lyme borreliosis. Archives of Neurology, 48, 1125-1129.

Leary, M. R., Patton, K. M., Orlando, A. E., \& Funk, W. W. (2000). The imposter phenomenon: Self-perceptions, reflected appraisals, and interpersonal strategies. Journal of Personality, 68, 725-774.

Mason, J. (2003). The use of a repertory grid as an aid to assessment and formulation in a sex offender with a learning disability. The British Journal of Forensic Practice, 5, 13-20.

Millon, T. (1996). Disorders of personality: DSM-IV and beyond (2nd ed.). New York: John Wiley.

Morf, C. C., \& Rhodewalt, F. (1993). Narcissism and self-evaluation maintenance: Explorations in object relations. Personality and Social Psychology Bulletin, 19, 668-676.

Morrison, J. (1997). When psychological problems mask medical disorders. New York: Guilford.

Rhodewalt, F., \& Morf, C. C. (1998). On self-aggrandizement and anger: A temporal analysis of narcissism and affective responses to success and failure. Journal of Personality and Social Psychology, 74, 672-685.

Rogers, C. R. (1952). Client-centered psychotherapy. Scientific American, 187, 66-74.

Rorschach, H. (1942). Psychodiagnostics: A diagnostic test based on perception. Berne, Switzerland: Huber. (Original work published 1921)

Rotter, J. B., \& Rafferty, J. E. (1950). Manual: The Rotter Incomplete Sentences Blank. New York: The Psychological Corporation.

Tager, F. A., \& Fallon, B. A. (2001). Psychiatric and cognitive features of Lyme disease. Psychiatric Annals, 31, 173-181.

Westervelt, H. J., \& McCaffrey, R. J. (2002). Neuropsychological functioning in chronic Lyme disease. Neuropsychology Review, 12, 153-177.

Wormser, G. P., Nadelman, R. B., Dattwyler, R. J., Dennis, D. T., Shapiro, E. D., Steere, A. C., et al. (2000). Practice guidelines for the treatment of Lyme disease. Clinical Infectious Diseases, 31, S1-S14.

Young, J. E., Weinberger, A. D., \& Beck, A. T. (2001). Cognitive therapy for depression. In D. H. Barlow (Ed.), Clinical handbook of psychological disorders: A step-by-step treatment manual (pp. 154-208). New York: Guilford.

Melissa J. Leedy, MS, is a doctoral candidate in the clinical psychology program at Oklahoma State University (OSU). She is completing her predoctoral internship at the James A. Haley VA in Tampa, Florida. Her clinical and research interests center on behavioral health psychology.

Melissa Jackson, BS, is a doctoral student in the clinical psychology program at Oklahoma State University (OSU) and is a member of the Behavior Change Laboratory. Her research interests include substance use, HIV/AIDS, and college drinking issues.

Jennifer L. Callahan, $\mathrm{PhD}$, ABPP is an assistant professor of psychology at the University of North Texas (UNT), Denton. She also holds a visiting appointment at Yale University School of Medicine in the Department of Psychiatry, New Haven, Connecticut. Her research interests span the assessment (clinical and neuropsychological) and psychotherapy domains, with particular emphasis on understanding clinical competencies and clinical training. 